\title{
"Inverse Strain Effect in Atomic Scale"-Enhanced Hydrogen Evolution Activity and Durability in Cu-Substituted Palladseite
}

Saurav Ch. Sarma, ${ }^{\dagger \neq} \neq$ Vidyanshu Mishra, ${ }^{\dagger, \ddagger 0}$ K. A. Ann Mary, ${ }^{\dagger}$ Soumyabrata Roy, ${ }^{\dagger, \ddagger}$ and Sebastian C. Peter*,,$+ \ddagger$ (i)

${ }^{\dagger}$ New Chemistry Unit, Jawaharlal Nehru Centre for Advanced Scientific Research, Jakkur, Bangalore 560064, India

${ }^{\ddagger}$ School of Advanced Materials, Jawaharlal Nehru Centre for Advanced Scientific Research, Jakkur, Bangalore 560064, India

Supporting Information

ABSTRACT: Since the preceding decade, strain engineering has been playing a vital role in modifying the activity of electrocatalysts. Incorporation of tensile strain into a Pd-based system usually requires substitution with larger atoms (usually a third row expensive transition metals). This work provides a unique strategy of introducing tensile strain by the substitution of small and low cost copper atoms (inverse strain effect) at the palladium sites of $\mathrm{Pd}_{17} \mathrm{Se}_{15}$. The $\mathrm{Pd}$ atom being in the +2 oxidation state adsorbs hydrogen very weakly, and $\mathrm{Se}$, in its elemental state, binds weakly to $\mathrm{H}^{*}$ adsorbate. However, the presence of Pd modulates the electronic structure of Se to have $\Delta G_{\mathrm{H}^{*}}$ close to 0 and favors the progress of the reaction. $\mathrm{Cu}$ substitution further lowers $\Delta G_{\mathrm{H}^{*}}$, thus favoring the reaction. This unique synergistic effect between the two processes is accountable for better activity, high stability of 30000 cycles and significantly high turnover frequency of $126.3 \mathrm{~s}^{-1}$ for $\left(\mathrm{CuPd}_{17} \mathrm{Se}_{15}\right.$.
$\mathrm{F}$ or several decades, a thrust exists within the scientific community to move toward the hydrogen economy. Hydrogen, being the environmentally cleaner source of energy, solves the pressing problem of carbonaceous emissions due to burning of conventional fossil fuels. The key to the success of the hydrogen economy lies in the cost-effective production of hydrogen, one of the best routes of which is through electrolysis of water. However, the state-of-the-art catalyst $\mathrm{Pt} / \mathrm{C}$ hinders the long-term and extensive commercialization of water electrolyzers because of its low abundance and high cost. Thus, the demand for cheaper, efficient, and sustainable alternatives to $\mathrm{Pt}$ has ushered in a fast-evolving area of catalyst engineering where many innovative designs have already shown promising potential to compete with the state-ofthe-art Pt catalyst toward electrochemical half-cell reactions. Activity and stability are the two important aspects of choosing an electrocatalyst.

It is well-known that the electrochemical activity of a catalyst can easily be altered by tuning the $d$-band center of the catalyst $^{1-4}$ through several chemical and structural modifications such as by varying particle size, inducing strain through doping, substitution, intercalation, and creating overlayers and interfaces. $^{4-7}$ Of the several approaches used to tune the $d$-band center and consequently enhance the electrocatalytic performance of a catalyst, inducing strain has proven to play a significant role. Application of strain (tensile/compressive) shifts the $d$ band center toward or away from the Fermi level and thus strengthens or weakens the metal-adsorbate bond. ${ }^{4}$ The importance of the metal-adsorbate bond can directly be assessed from the Sabatier principle, which states that the bonding should be neither too strong nor too weak. ${ }^{8}$ Yan et al. directly demonstrated the effect of tensile and compressive strain on electrocatalytic activity of WC toward the hydrogen evolution reaction (HER). ${ }^{9}$ Similarly, Zhu et al. induced tensile surface strain in $\mathrm{Co}_{9} \mathrm{~S}_{8} / \mathrm{MoS}_{2}$ core/shell nanocrystals by changing the $\mathrm{MoS}_{2}$ layer thickness from 5 to $1 \mathrm{~L}^{10}$ Incorporating strain through substitution or doping is also prevalent in literature. For example, ultrathin $\mathrm{Pt}-\mathrm{M}(\mathrm{M}=\mathrm{Ni}$, $\mathrm{Co}, \mathrm{Fe}){ }^{11} \mathrm{RuP}_{2} @ \mathrm{NPC},{ }^{12} \mathrm{~W}\left(\mathrm{Se}_{x} \mathrm{~S}_{1-x}\right)_{2},{ }^{5} \mathrm{Zn}$-doped $\mathrm{Co}_{3} \mathrm{~S}_{4}{ }^{13}$ Co-doped $\mathrm{MoS}_{2}$ /F-ITO, ${ }^{14} \mathrm{MoS}_{2} @ \mathrm{Pt}$, ${ }^{6}$ Mo-doped $\mathrm{W}_{18} \mathrm{O}_{49}{ }^{15}$

Received: October 14, 2018

Accepted: November 8, 2018

Published: November 8, 2018 
and Co-doped $\mathrm{NiSe}_{2}{ }^{16}$ have been found to exhibit enhanced activity compared to those of their pristine compounds. Thus, choosing a suitable dopant is an important criterion toward tuning bond strength, which in turn causes dramatic improvement in the catalytic activity toward HER. Irrespective of superior activity during the initial stage, electrocatalysts are subject to quick activity loss during prolonged cycling, the reasons for which are mainly attributed to catalyst surface poisoning and surface degradation.

The stability of a catalyst, which is arguably the most dominant factor toward commercialization, is often overlooked by the scientific community. Liu et al. reported the synthesis of $\mathrm{CoSIP} /$ carbon nanotube (CNT) that shows stability for 2000 cycles. ${ }^{17}$ Many other catalysts such as $\mathrm{Pt}-\mathrm{MoS}_{x}(1000$ cycles $){ }^{2}$ MoPIS (1000 cycles), ${ }^{18} \mathrm{PdCu} @ P d(5000$ cycles $),{ }^{19} \mathrm{NiRu} @ \mathrm{~N}-$ $\mathrm{C}(1000$ cycles $),{ }^{20} \mathrm{~N}$-doped $\mathrm{CoS}_{2}$ nanowire arrays (3000 cycles), ${ }^{21} \mathrm{Mo}_{2} \mathrm{C} / \mathrm{CNT}$ (1000 cycles), ${ }^{22} \mathrm{Ni}_{3} \mathrm{FeN} / \mathrm{r}-\mathrm{GO},{ }^{23}$ structurally deformed $\mathrm{MoS}_{2}$ (5000 cycles), ${ }^{24}$ nanoporous CuTi (5000 cycles), $\mathrm{Pd}-\mathrm{CN}_{x}$ (10000 cycles), ${ }^{1} \mathrm{Ni}_{3} \mathrm{~S}_{2}$ nanosheets array $(10000$ cycles $),{ }^{25} \mathrm{Ru} / \mathrm{CeO}_{2}$ (10000 cycles), ${ }^{26}$ $\mathrm{Co}_{9} \mathrm{~S}_{8} / \mathrm{NC} @ \mathrm{MoS}_{2}{ }^{27}$ and $\mathrm{Mn}-\mathrm{CoS}_{2}(10000 \text { cycles })^{28}$ also showed similar stabilities.

In this work, we report the synthesis of Cu-substituted $\mathrm{Pd}_{17} \mathrm{Se}_{15}\left((\mathrm{CuPd})_{17} \mathrm{Se}_{15}\right)$ nanoparticles that show enhanced activity, high current density, high turnover frequency (126.3 $\mathrm{s}^{-1}$ ), and superior stability of 30000 sweeps toward HER. We tried to address the following scientific points in this work.

(i) Exact site of substitution by $\mathrm{Cu}$ in $\mathrm{Pd}_{17} \mathrm{Se}_{15}$ lattice. Detailed powder X-ray diffraction (PXRD) analysis together with $\mathrm{X}$-ray absorption spectroscopy (XAS) study revealed the site of substitution.

(ii) The effect of $\mathrm{Cu}$ substitution on the structure and oxidation state. In situ X-ray absorption near-edge spectroscopy (XANES) and DFT calculation analysis revealed the dynamic changes happening on the catalyst surface during electrochemical measurements.

(iii) The driving force for the enhancement of the electrocatalytic activity. This has been done through a combined experimental and theoretical approach. Unexpected tensile stress induced by the copper substitution and its electronic effect are the key reasons for the enhanced activity and stability compared to those of the pristine compound. Selective copper dissolution further improves the activity generating a very stable catalyst surface for the electrochemical HER that shows stability for $30000 \mathrm{CV}$ cycles.

We believe that the present study provides a unique way to understand the role of substitution in a lattice at the atomic level and arms us with several degrees of freedom to tune the catalytic activity and stability.

In general, doping/substitution/intercalation of a metal in a compound is clearly reflected by the change in lattice parameters of its unit cell, which completely depends on the size of the substituting metal. This is one of the fundamental ways to design new materials for selected application, and we have exploited a similar strategy in the present work. Copper has a smaller size (atomic radius $=128 \mathrm{pm}$ ) compared to that of palladium (atomic radius $=163 \mathrm{pm}$ ) or selenium (atomic radius $=190$ $\mathrm{pm}$ ). Thus, the interplanar distance in the $\mathrm{Pd}_{17} \mathrm{Se}_{15}$ lattice is expected to exhibit a decrease with $\mathrm{Cu}$ substitution/doping or anisotropic enhancement in the case of intercalation. Since no peaks corresponding to the $\mathrm{Cu}$ metal were observed in the powder XRD pattern (Figure S2), the possibility of intercalation could be easily eliminated. The compound shows reflection profiles consistent with a $P m \overline{3} m$ crystal space-group symmetry. Profile matching of the experimental powder XRD pattern in Figure $1 \mathrm{a}, \mathrm{b}$ shows an increase in the lattice parameters of the
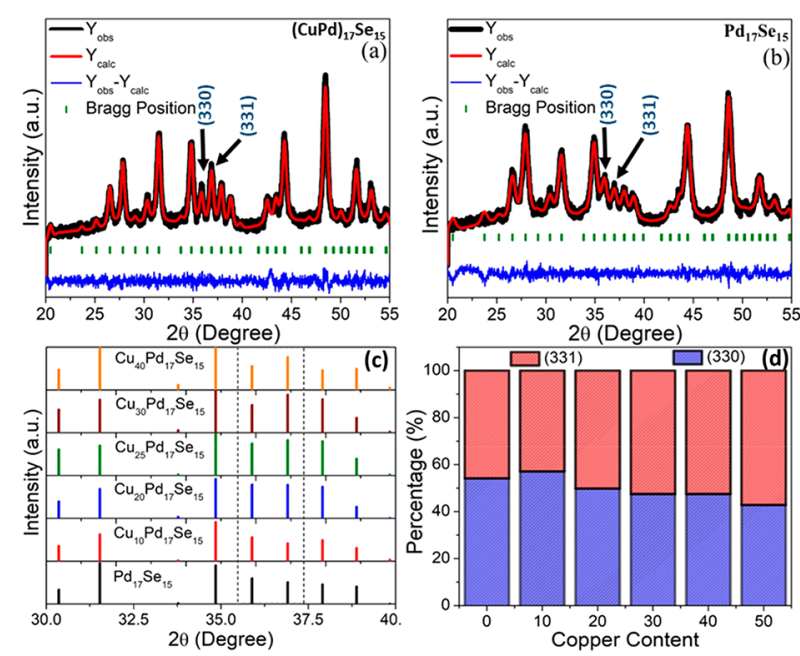

(e)
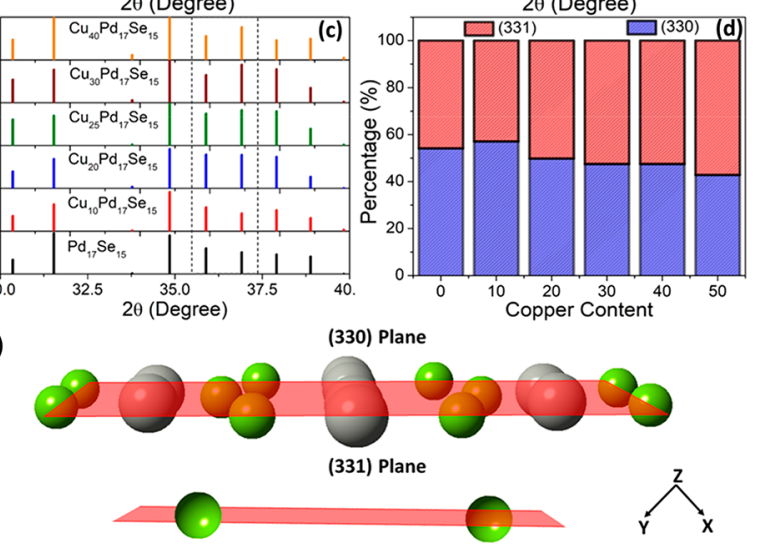

Figure 1. Profile matching of the PXRD pattern of $(\mathrm{a})(\mathrm{CuPd})_{17} \mathrm{Se}_{15}$ and $(\mathrm{b})$ pristine $\mathrm{Pd}_{17} \mathrm{Se}_{15}$. Lattice parameters increased from $10.59 \AA$ in pristine $\mathrm{Pd}_{17} \mathrm{Se}_{15}$ to $10.63 \AA$ in $(\mathrm{CuPd})_{17} \mathrm{Se}_{15}$. (c) Simulated PXRD pattern showing the variation in the intensity of PXRD peaks mainly (330) and (331) with variation in Cu substitution. (d) Plot of ratio of intensity of (331):(330) with varying $\mathrm{Cu}$ substitution and (e) schematic representation of (330) and (331) crystallographic planes of $(\mathrm{CuPd})_{17} \mathrm{Se}_{15}$.

unit cell, from 10.59 to $10.63 \AA$ after $\mathrm{Cu}$ substitution, consistent with the negative shift in PXRD pattern. Thus, contrary to the normal trend (Table S1), it is observed that the interplanar distance in $\mathrm{Pd}_{17} \mathrm{Se}_{15}$ increases upon $\mathrm{Cu}$ substitution and the system may apparently be under tensile strain due to $\mathrm{Cu}$ substitution. This is further evident from the negative shift of PXRD peak positions (Figure S2). Besides, intensities of a few peaks differ from that of the simulated pattern. To see the influence of $\mathrm{Cu}$ substitution on the PXRD pattern, the ATK VNL program suite ${ }^{29}$ was used to simulate the PXRD pattern of a different percentage of the $\mathrm{Cu}$-substituted $\mathrm{Pd}_{17} \mathrm{Se}_{15}$ lattice and is presented in Figure 1c. (331) and (330) are taken as the representative crystallographic planes due to significant difference upon $\mathrm{Cu}$ substitution. A similar trend in the intensity ratio of $(331) /(330)$ was observed in the case of simulated patterns, as illustrated in Figure 1d. Since the intensity of the XRD peak depends upon the scattering and multiplicity factors of a crystal plane, it is expected that the reduction in the peak intensity can be due to the contribution from both. Intensity of the (330) peak decreases with an increase in $\mathrm{Cu}$ substitution. These planes have the highest planar density of Pd atom. Hence, they are highly affected by $\mathrm{Cu}$ substitution and this changes the mean atomic scattering intensity from the corresponding planes compared to that of its pristine compound. Therefore, the intensity of the peaks with higher planar density of $\mathrm{Pd}$ atom 
decreases compared to those of the other peaks (as represented by (330) and (331) planes in Figure 1e).

Figure $\mathrm{S} 3 \mathrm{a}-\mathrm{d}$ shows transmission electron microscopy (TEM) images of the $\mathrm{Cu}$-substituted compound. The $d$-spacing calculated from the high resolution TEM (HRTEM) is $10.65 \AA$, which corresponds to the (100) crystallographic plane. Selected area electron diffraction presents crowded polycentric rings, which are due to a larger number of atoms within a unit cell (64 atoms), which gives rise to a larger number of diffraction planes. Unsubstituted $\mathrm{Pd}_{17} \mathrm{Se}_{15}$ has a Pd atomic percentage of $53.13 \%$, and as seen from energy dispersive analysis X-ray (EDAX) data in Figure S3e, only $15.66 \%$ of $\mathrm{Cu}$ substitutes $\mathrm{Pd}$, which is nearly one-fourth the total Pd in the system (25\% substitution of Pd atoms). Thus, it can be assumed that one-fourth of the Pd atoms are replaced by $\mathrm{Cu}$. Figure S4 shows the core-level XPS spectra of $\mathrm{Cu} 2 \mathrm{p}, \mathrm{Pd} 3 \mathrm{~d}$, and Se 3d. Dividing by the relative sensitivity factor gives a composition of $\mathrm{Cu}: \mathrm{Pd}: \mathrm{Se}=0.37: 1.00: 1.09$.

Hydrogen Evolution Reaction (HER). Electrochemical HER activity of the catalyst has been investigated in $0.5 \mathrm{M} \mathrm{H}_{2} \mathrm{SO}_{4}$ setup using a three-electrode configuration. After the electrochemical cell was assembled, 80 activation cyclic voltammetry (CV) cycles (at $50 \mathrm{mV} / \mathrm{s}$ in the range +0.1 to $-0.55 \mathrm{~V}$ vs reference hydrogen electrode (RHE)) were run to ascertain that steady state was reached. All the electrochemical measurements were recorded once the steady state was reached. The selective electrochemical dissolution (dealloying) of $\mathrm{Cu}$, during the electrochemical activation procedure, is the key process in the formation of the active catalyst. As shown in Figure 2a, the intensity of the $\mathrm{Cu}$ dissolution peak $(0.46-0.625 \mathrm{~V}$ vs RHE in the forward scan) decreases gradually with the increasing number of potential cycles, indicating $\mathrm{Cu}$ dissolution from $(\mathrm{CuPd})_{17} \mathrm{Se}_{15}$ NPs. Activity of the catalyst increases upon $\mathrm{Cu}$ dissolution, as shown in Figure $2 \mathrm{~b}$. All the electrochemistry from now on has been recorded on the dealloyed catalyst.

Figure $2 \mathrm{~b}$ shows the polarization curve of the catalyst before and after the activation process with a consecutive interval of 20 cycles. The onset potential of the catalyst decreases by $60 \mathrm{mV}$ after 80 cycles of activation. The onset potential was calculated as the potential required to reach $0.1 \mathrm{~mA} \mathrm{~cm}{ }^{-2}$ current density, which is found to be around $85.4 \mathrm{mV}$, which decreased to 76.1 $\mathrm{mV}$ after 10000 cycles and remained stable thereafter. A current density of $10 \mathrm{~mA} \mathrm{~cm}^{-2}$ was achieved at an overpotential of 188.5 $\mathrm{mV}$. Figure $2 \mathrm{c}$ shows the positive shift of the onset potential of $\mathrm{Pd}_{17} \mathrm{Se}_{15}$ after $\mathrm{Cu}$ substitution.

Dealloyed $(\mathrm{CuPd})_{17} \mathrm{Se}_{15}$ shows a Tafel slope value of $48 \mathrm{mV}$ $\mathrm{dec}^{-1}$, which is close to that of $\mathrm{Pt} / \mathrm{C}\left(29 \mathrm{mV} \mathrm{dec}^{-1}\right)$ and much improved from the pristine $\mathrm{Pd}_{17} \mathrm{Se}_{15}\left(71.2 \mathrm{mV} \mathrm{dec}^{-1}\right)$ and

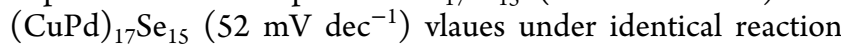
conditions.

Hence, the value of the Tafel slope clearly indicates that HER on the dealloyed catalyst follows the Volmer-Heyrovsky mechanism, with electrochemical desorption of hydrogen as the rate-limiting step. ${ }^{30}$ Impedance spectroscopic data show the charge-transfer resistance for the $\mathrm{Cu}$-substituted catalysts (58.8 $\Omega$ ) to be less than half of the $R_{\mathrm{ct}}$ value $(179.6 \Omega)$ for the pristine compound (Figure 2e), confirming that faster charge-transfer kinetics for the $\mathrm{Cu}$-substituted compound is beneficial for the efficient charge transfer, which is in good agreement with the low Tafel slopes.

The TOF is the ideal figure of merit to correlate the intrinsic activities of different catalyst materials. The TOF for the substituted compound reaches $0.19,2.05$, and $126.3 \mathrm{~s}^{-1}$ at overpotentials of 0,100 , and $200 \mathrm{mV}$, respectively, which is
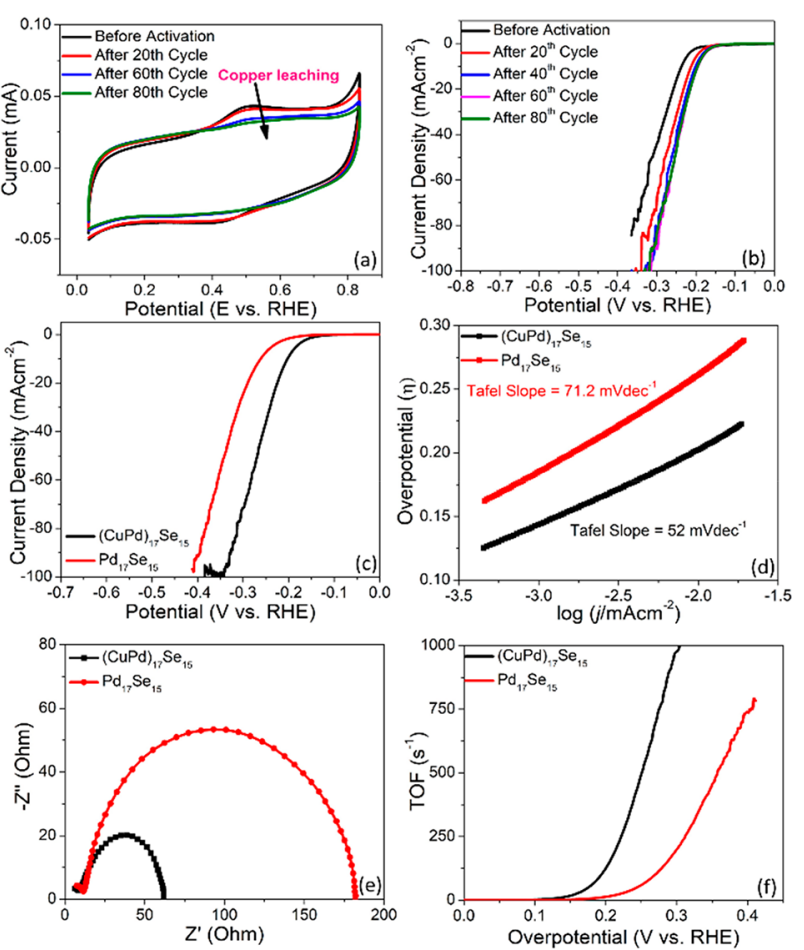

Figure 2. (a) Cyclic voltammogram recorded at a scan rate of 0.05 $\mathrm{V} / \mathrm{s}$ in $0.5 \mathrm{M} \mathrm{H}_{2} \mathrm{SO}_{4}$ showing the oxidative removal of $\mathrm{Cu}$ from the system during the activation cycles. A steady state was achieved after 80 cycles. (b) Polarization curve showing the activation of the catalyst after every 20 cycles until stable curve is achieved. (c) Comparison of linear sweep voltammetry (LSV) plots showing positive shift in the onset potential for $(\mathrm{CuPd})_{17} \mathrm{Se}_{15}$ compared to $\mathrm{Pd}_{17} \mathrm{Se}_{15}$. (d) Comparison of the Tafel slopes of the catalyst before and after the accelerated degradation test. (e) Electrochemical impedance spectra (EIS) showing the decrease in charge-transfer resistance of the $\mathrm{Cu}$-substituted catalyst. (f) Time of flight (TOF) value of $\mathrm{Pd}_{17} \mathrm{Se}_{15}$ and $(\mathrm{CuPd})_{17} \mathrm{Se}_{15}$ showing improvement in the catalytic behavior after $\mathrm{Cu}$ substitution.

several times higher than that in the pristine $\mathrm{Pd}_{17} \mathrm{Se}_{15}$ (Figure 2f). The TOF for the carbon support was calculated and found to be too low to have any appreciable effect on the TOF of the compound and hence it is neglected. Comparison of the TOF value with that the $\mathrm{Pd}_{17} \mathrm{Se}_{15}$ is presented in Table S2. The TOF calculated for the dealloyed $(\mathrm{CuPd})_{17} \mathrm{Se}_{15}$ is much higher than those for previously reported compounds such as Au $\left(0.3 \mathrm{~s}^{-1} @\right.$ $200 \mathrm{mV}),{ }^{31} \mathrm{AuNi}\left(0.0334 \mathrm{~s}^{-1} @ 80 \mathrm{mV}\right),{ }^{32} \mathrm{Ni}_{2} \mathrm{P}\left(0.015 \mathrm{~s}^{-1} @\right.$ $100 \mathrm{mV}),{ }^{33} \mathrm{P} / \mathrm{Se}-\mathrm{MoS}_{2} / \mathrm{CFP}\left(0.4 \mathrm{~s}^{-1} @ 150 \mathrm{mV}\right){ }^{34} \mathrm{CoPS}$ $\left(3.38 \mathrm{~s}^{-1} @ 100 \mathrm{mV}\right),{ }^{35} \mathrm{Ru} / \mathrm{MeOH} / \mathrm{THF}\left(0.87 \mathrm{~s}^{-1} @ 100\right.$ $\mathrm{mV}),{ }^{36}$ and $\mathrm{Ni}-\mathrm{C}-\mathrm{N}$ (6.67@200 mV). ${ }^{37}$

Structural Changes upon $\mathrm{Cu}$ Substitution. Better activity of the $\mathrm{Cu}$-substituted compound can be envisaged by simulating the coordination environment around Se. Density functional theory (DFT) calculation was used to relax the cell parameters of the unit cell after $25 \%$ substitution of $\mathrm{Pd}$ atoms with $\mathrm{Cu}$ in the unit cell. Se in $\mathrm{Pd}_{17} \mathrm{Se}_{15}$ is found to exist in three different coordination environments: one tetrahedral and two distorted square pyramidal. Figure S5 shows the coordination environment around Se before and after $\mathrm{Cu}$ substitution.

It must be noted that after structural optimization, $\mathrm{Cu}-\mathrm{Se}$ has a smaller bond length compared to Pd-Se bonds. The decrease in the $\mathrm{Cu}-\mathrm{Se}$ bond length $(2.4120-2.4480 \AA$ in the tetrahedral arrangement and $2.4860-2.5160 \AA$ in square pyramidal arrangement), compared to the $\mathrm{Pd}-\mathrm{Se}$ bond length, is because 

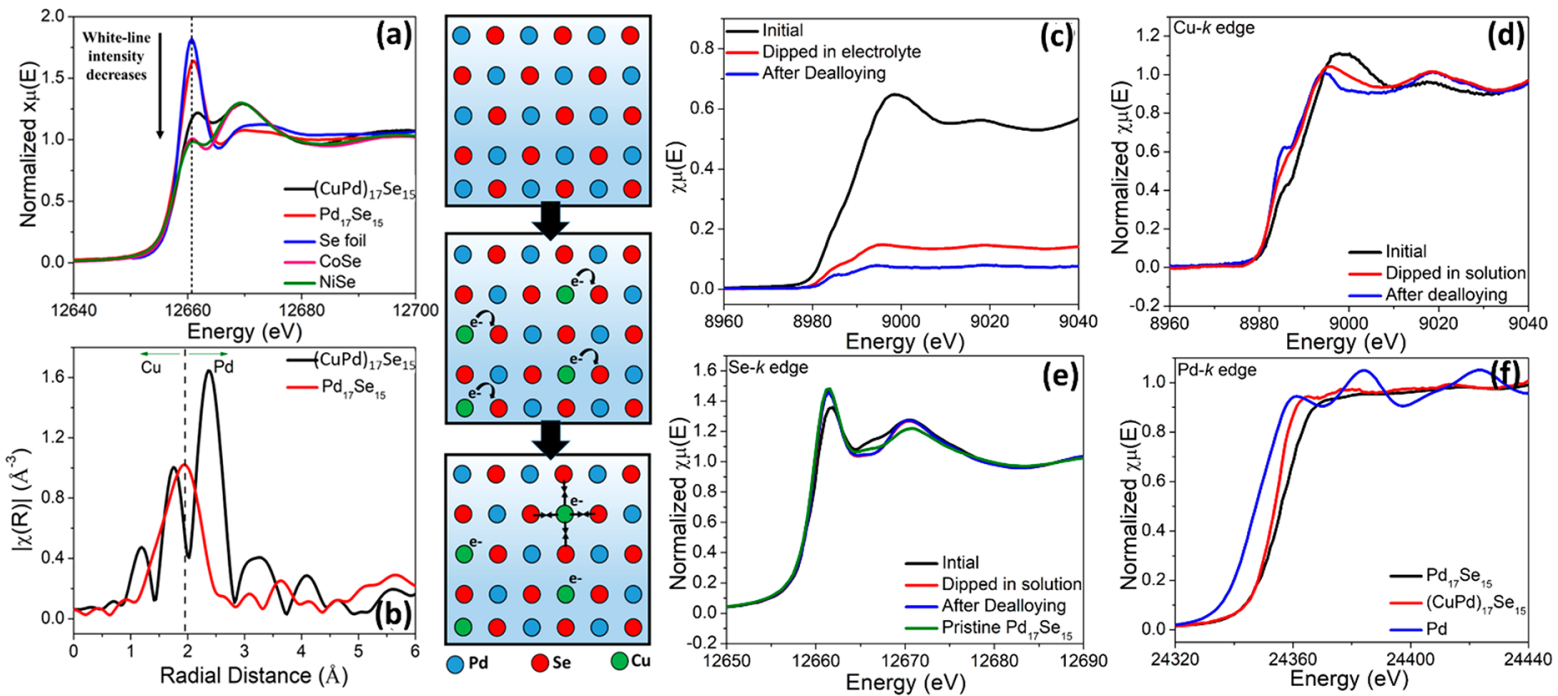

Figure 3. (a) X-ray absorption near edge spectroscopy of Se K-edge of Se foil, $\mathrm{Pd}_{17} \mathrm{Se}_{15},(\mathrm{CuPd})_{17} \mathrm{Se}_{15}$, CoSe, and NiSe. Comparison of changes in white-line intensity gives a relative idea about the change in oxidation state of $S e$ in various compounds ranging from 0 oxidation state in Se foil to -2 oxidation state in CoSe and NiSe. (b) Fourier transformed $R$-space data showing the appearance of a Se-Cu peak at a lower radial distance and a $\mathrm{Se}-\mathrm{Pd}$ peak at a higher radial distance than for the pristine compound and schematic showing the effect of copper substitution in the $\mathrm{Pd}_{17} \mathrm{Se}_{15}$ lattice. In situ XANES spectra of $(\mathrm{CuPd})_{17} \mathrm{Se}_{15}$ showing change in the oxidation state happening to the constituent elements. (c) Unnormalized $\mathrm{Cu}$ K-edge XANES spectra showing the chemical dissolution of $\mathrm{Cu}$. (d) Normalized Cu K-edge XANES spectra showing the shift in edge energy during the electrochemical process. (e) Se K-edge XANES spectra showing the variation in oxidation state of the Se. (f) Ex situ Pd K-edge XANES spectra showing the intermediate oxidation state of $\mathrm{Pd}$ in $(\mathrm{CuPd})_{17} \mathrm{Se}_{15}$.

of the increase in charge transfer from $\mathrm{Cu}$ to Se owing to substantial electronegativity difference between the two. Henceforth, the increase in the electron density around Se decreases the effective nuclear charge exerted by the nucleus, thereby increasing the Pd-Se bond distance (from 2.4930 to $2.5770 \AA$ to 2.5110-2.5770 $\AA$ after $\mathrm{Cu}$ substitution as seen from DFT calculation). Figure $\mathrm{S} 6$ shows the domino effect of elongation of $\mathrm{Pd}-\mathrm{Se}$ bond length that traverses along the $\mathrm{Pd}-\mathrm{Se}$ chain length to finally increase the edge length of the unit cell. Therefore, the system experiences tensile stress. This corroborates well with the increase in cell parameters obtained from profile matching of the PXRD pattern.

Change in Oxidation State upon Copper Substitution. The white-line intensity in the Se K-edge XANES pattern corresponds to the $1 \mathrm{~s} \rightarrow 4 \mathrm{p}$ electronic transition. The higher the number of electrons in the p-orbital (higher the negative oxidation state), the lower is the white-line intensity. Figure 3a indicates that the Se foil has the highest white-line intensity followed by $\mathrm{Pd}_{17} \mathrm{Se}_{15}$ and $(\mathrm{CuPd})_{17} \mathrm{Se}_{15}$. NiSe and CoSe listed in Figure $3 \mathrm{a}$ have -2 oxidation states and are used as references for determining the oxidation state in $(\mathrm{CuPd})_{17} \mathrm{Se}_{15}$. Thus, it is reasonable to anticipate that $\mathrm{Se}$ in $(\mathrm{CuPd})_{17} \mathrm{Se}_{15}$ has a higher negative oxidation state compared to that in pristine $\operatorname{Pd}_{17} \mathrm{Se}_{15}$. This indicates the increase in charge transfer from $\mathrm{Cu}$ to $\mathrm{Se}$, which is possible only when $\mathrm{Cu}$ and $\mathrm{Se}$ are close to each other and is also confirmed from the theoretical calculation. This, sequentially, decreases the effective nuclear charge around Se. Thus, the $\mathrm{Pd}-$ Se bond distance increases, which is evident from the radial distribution function of EXAFS spectra shown in Figure $3 \mathrm{~b} . \mathrm{Pd}_{17} \mathrm{Se}_{15}$ has a single peak in $R$-space that splits to two peaks in the case of $(\mathrm{CuPd})_{17} \mathrm{Se}_{15}$, one having a lower and another a higher bond distance corresponding to $\mathrm{Se}-\mathrm{Cu}$ and $\mathrm{Se}-\mathrm{Pd}$ bond distances, respectively. This is evident from the structural parameters obtained from the fitted first coordination shell (Table S3). The Pd-Se scattering path increase in distance (from its ideal position of $2.433 \AA$ to $2.458 \AA$ ), while the $\mathrm{Se}-\mathrm{Cu}$ scattering path decreases in bond distance (from its ideal position of $2.118 \AA$ to $1.951 \AA$ ) (Figure S7).

In order to investigate the chemical changes during the dealloying process, in situ XAS study of the compound was performed. Figure $3 c$ shows the unnormalized $\mathrm{Cu}$ K-edge XANES pattern of the compound before and after electrochemical measurements. A decrease in the edge jump of the spectra, when $\mathrm{Cu}$ is dipped in $0.5 \mathrm{M} \mathrm{H}_{2} \mathrm{SO}_{4}$ solution, is attributed to the dissolution of $\mathrm{Cu}$ (II) in the acidic electrolyte, thus reducing the amount of $\mathrm{Cu}$ in the sample. Comparing the energies $\left(E_{0}\right)$ in the normalized $\mathrm{Cu}$ K-edge XANES spectra (Figure $3 \mathrm{~d}$ ), we find that $\mathrm{Cu}$ in the compound before the electrochemical treatment exhibits both +1 and +2 oxidation states. When dipped into the acidic electrolyte, $\mathrm{Cu}(\mathrm{II})$ dissolves into the acidic electrolyte, leaving behind $\mathrm{Cu}$ in predominantly the +1 oxidation state in the catalyst. This is clearly detected in the shoulder peak, observed in the XANES pattern, attributed to $1 \mathrm{~s} \rightarrow 4 \mathrm{p}_{z}$ transition. ${ }^{38}$ The peak becomes predominant after the dealloying process. Se K-edge XANES spectra of the compound show that when $\mathrm{Cu}$ is dipped in acidic electrolyte, the white-line intensity increases and reaches the same height as in pristine $\mathrm{Pd}_{17} \mathrm{Se}_{15}$, indicating $\mathrm{Se}$ is in the same oxidation state as in $\mathrm{Pd}_{17} \mathrm{Se}_{15}$ (as shown in Figure 3e). The comparison of Pd K-edge XANES spectra of $\mathrm{Pd}$ foil, pristine $\mathrm{Pd}_{17} \mathrm{Se}_{15}$, and $(\mathrm{CuPd})_{17} \mathrm{Se}_{15}$ (Figure $3 \mathrm{f}$ ) reveals an intermediate oxidation state between 0 and +2 for $\mathrm{Pd}$ in $(\mathrm{CuPd})_{17} \mathrm{Se}_{15}$.

In addition to electronic effects, the morphological effect such as increase in surface area, electrochemically active surface area (ECSA) in this case, may also contribute to the enhanced activity due to $\mathrm{Cu}$ substitution. The assessment of the ECSA of the samples was carried out by running cyclic voltammetry $(\mathrm{CV})$ measurements at various scan rates $(20,40,60,80$, and $100 \mathrm{mV}$ $\mathrm{s}^{-1}$ ) in the nonfaradaic region $0.03-0.23 \mathrm{~V}$ vs RHE where the current response is mostly due to the charging of the double layer. The double-layer capacitance was calculated by plotting 
(a)

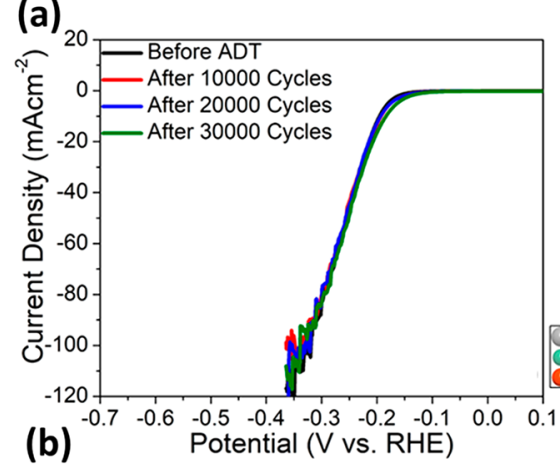

(c)
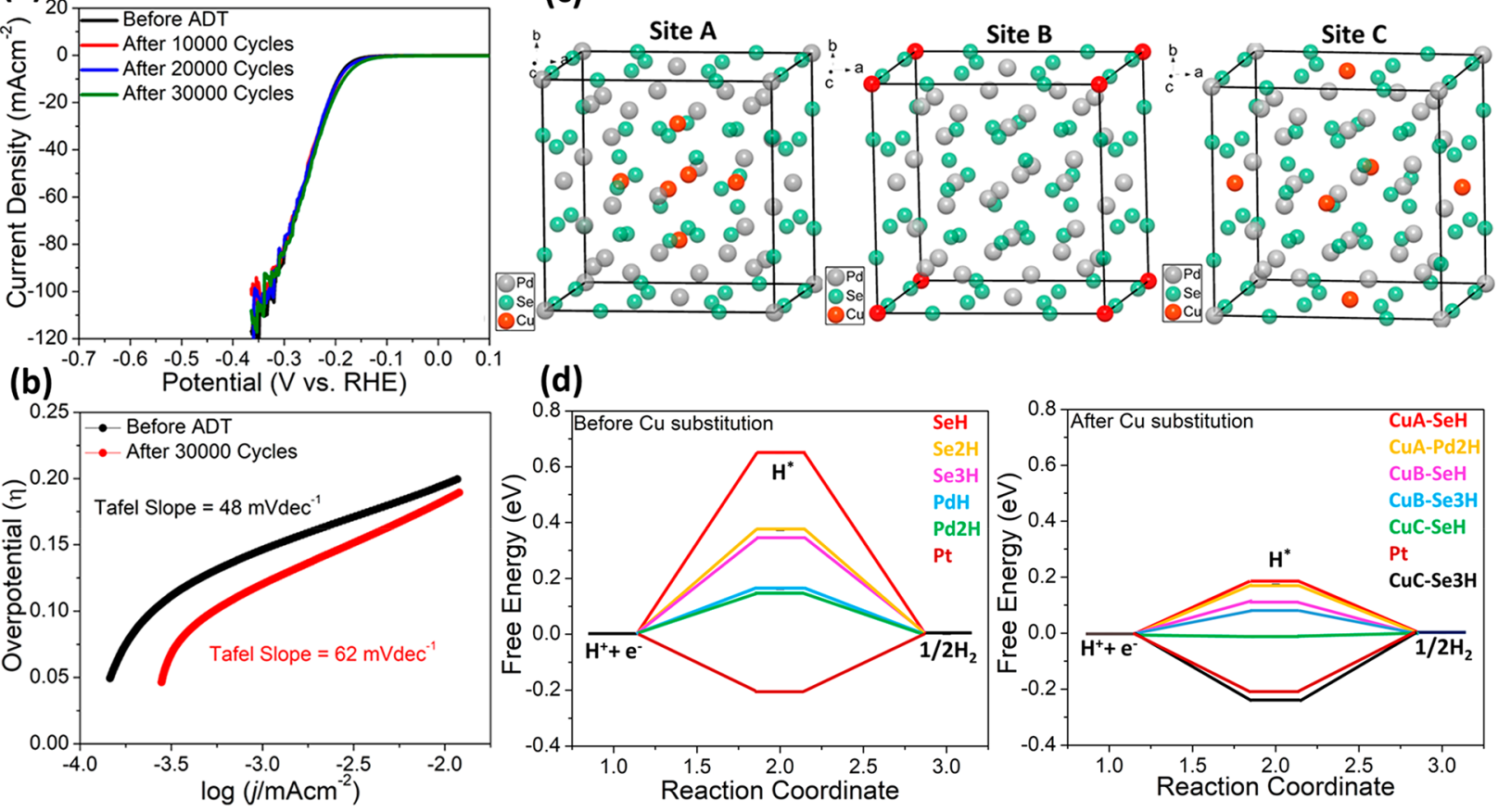

Figure 4. (a) Linear sweep voltammogram of the Cu-substituted catalyst showing prolonged stability of the catalyst even after $30000 \mathrm{cycles}$ and (b) comparison of the Tafel slopes of the catalyst before and after the degradation test. (c) Schematic representation of different possible sites of $\mathrm{Cu}$ substitution and (d) comparison of the changes in Gibbs free energy of adsorption of $\mathbf{H}^{*}$ before and after $\mathrm{Cu}$ substitution.

the $\frac{1}{2} \Delta J$, i.e., $\frac{1}{2}\left(J_{\mathrm{a}}-J_{\mathrm{c}}\right)$, where $J_{\mathrm{a}}$ and $J_{\mathrm{c}}$ are cathodic and anodic current, respectively, at $0.15 \mathrm{~V}$ vs RHE against the scan rate (Figure S8). ${ }^{39}$ It is well-known that $C_{\mathrm{dl}}$ is directly proportional to the ECSA. Hence, a lower value of $C_{\mathrm{dl}}$ for the Cu-substituted compound $\left(0.336 \mathrm{mF} \mathrm{cm} \mathrm{cm}^{-2}\right)$ compared to that of the pristine compound $\left(0.498 \mathrm{mF} \mathrm{cm}^{-2}\right)$ suggests that enhancement in the activity of the substituted compound is purely due to the electronic effect that resulted from the tensile stress and electronic effect in the system imposed by the $\mathrm{Cu}$ atoms.

Electrochemical Stability. Performance stability tests of a dealloyed $(\mathrm{CuPd})_{17} \mathrm{Se}_{15}$ catalyst was checked for 30000 potential cycles (Figure $4 \mathrm{a}$ ), between 0 and $-0.4 \mathrm{~V}$ vs RHE, with no change in the activity of the catalyst exhibiting ultrahigh stability for a prolonged time. This Tafel slope of the catalyst has been increased from $48 \mathrm{mV} \mathrm{dec}^{-1}$, in the dealloyed catalyst, to 62 $\mathrm{mV} \mathrm{dec}{ }^{-1}$ after the degradation test, as illustrated in Figure $4 \mathrm{~b}$.

The commercial application of any catalyst can be extended if it can be used over a wide $\mathrm{pH}$ range. In this direction, the activity of the catalyst was also checked in an alkaline electrolyte of $0.5 \mathrm{M}$ $\mathrm{KOH}$. Interestingly, the catalyst was found to show a current density of $10 \mathrm{~mA} \mathrm{~cm}^{-2}$ at an overpotential of $375 \mathrm{mV}$, which remains almost the same even after 30000 cycles. Slight negative shift in the polarization curve shown in Figure S9 shows the high stability of the catalyst even in alkaline medium. Faradaic efficiency in the case of $(\mathrm{CuPd})_{17} \mathrm{Se}_{15}$ is calculated to be close to $100 \%$ and shown in Figures S10 and S11.

Theoretical Calculation. DFT calculation was executed through substitution of equivalent sites of $\mathrm{Pd}$ with $\mathrm{Cu}$. Since there are four types of $\mathrm{Pd}$ in the lattice, substitution in the four equivalent sites is possible. But we neglected one of the site as it contributes to more than $25 \%$ of substitution of Pd. Thus, we end up with three different possibilities of $\mathrm{Cu}$ substitution, namely, $\mathrm{CuA}, \mathrm{CuB}$, and $\mathrm{CuC}$, as represented in Figure 4c. In all the cases, the lattice parameter of the unit cell increased after $\mathrm{Cu}$ substitution from $10.606 \AA\left(\mathrm{Pd}_{17} \mathrm{Se}_{15}\right)$ to $10.6904 \AA(\mathrm{CuA})$, $10.7155 \AA(\mathrm{CuB})$, and $10.7156 \AA(\mathrm{CuC})$. Cu leaching further increased the lattice parameter, as shown in Table S4. According to Nørskov, ${ }^{3}$ an increase in the lattice parameter shifts the $d$ band center toward the Fermi level. This results in a decrease in the occupation of antibonding orbitals and hence a stronger metal-adsorbate bond. This is reflected by the $\Delta G_{\mathrm{H}}$ adsorption calculation, which is presented in Figure 4d. It is clearly observed that the number of active sites having optimal adsorption has increased after the $\mathrm{Cu}$ substitution. Due to $d$-band center shift toward the Fermi level, $\mathrm{Se}-\mathrm{H}$ bonds get stronger and Se starts acting as the active site. Only few of the Pd sites have an optimal adsorption toward $\mathrm{H}^{*}$. Unlike in $\mathrm{Pd}_{17} \mathrm{Se}_{15}, \mathrm{Pd}$ in $(\mathrm{CuPd})_{17} \mathrm{Se}_{15}$ has an intermediate oxidation state between 0 and +2 , as observed from Pd K-edge XANES data; hence, it weakly adsorbs $\mathrm{H}^{*}$. This indicates that a few of the $\mathrm{Pd}$ sites are activated after $\mathrm{Cu}$ substitution. To justify that $\mathrm{Pd}$ is not mainly the active sites, $\mathrm{Pd}$ sites were blocked electrochemically by $\mathrm{CO}$ adsorption and the activity was tested as shown in Figure S12a,b. A slight left shift in the onset potential was observed as only few Pd sites were active and got blocked. The remarks made in this work further explain the observation made by Kukunuri et al. ${ }^{40}$ They observed a considerable amount of Se DOS contribution near the Fermi level. In addition, the hydrogen adsorption/desorption peaks, as observed for Pd/Pt-based compounds were not observed for this compound. This supports the fact that only few Pd and mainly Se act as the active sites for the HER. Since Se mainly acts as the active site, the $d$-band model proposed by Hammer and Nørskov $^{3}$ was applied and strain and ligand effects were deconvoluted on these sites and presented in Figure 5..$^{41,42}$ $\mathrm{Se}^{\mathrm{II}}$ in $\mathrm{CuA}, \mathrm{Se}^{\mathrm{III}}$ in $\mathrm{Cu} \mathrm{B}$, and $\mathrm{Se}^{\mathrm{I}}$ in $\mathrm{Cu} \mathrm{C}$ are directly connected to $\mathrm{Cu}$ in the doped system. Hence, they exhibit the highest ligand effect. Se atoms further away from the $\mathrm{Cu}$ remain unaffected from the ligand effect. They experience only the strain effect. $\mathrm{Se}^{\mathrm{I}}$ in $\mathrm{Cu} \mathrm{A}, \mathrm{Se}^{\mathrm{I}}$ in $\mathrm{Cu} \mathrm{B}$, and $\mathrm{Se}^{\mathrm{III}}$ in $\mathrm{Cu} \mathrm{C}$ have their 


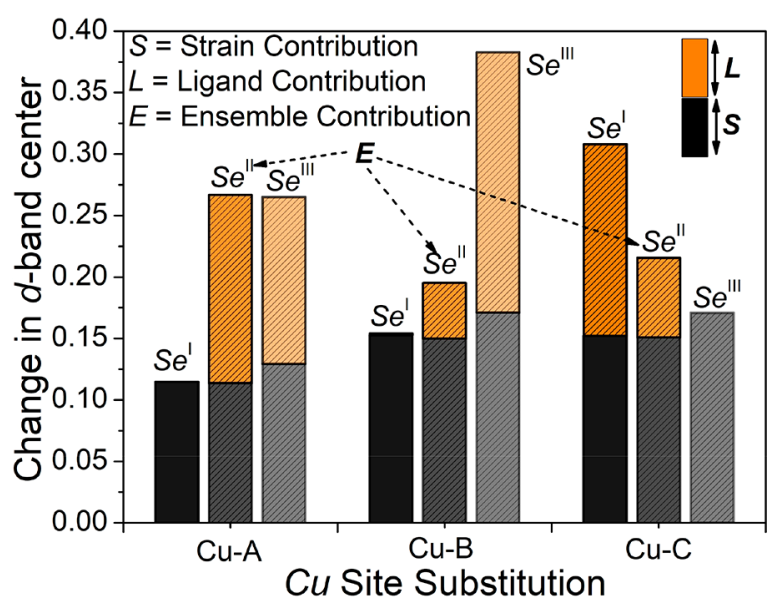

Figure 5. Deconvolution of strain, ligand and ensemble effect on Se sites of $(\mathrm{CuPd})_{17} \mathrm{Se}_{15} . \mathrm{S}, \mathrm{L}$, and $\mathrm{E}$ in the figure represents strain, ligand, and ensemble effect, respectively. $\mathrm{Se}^{\mathrm{I}}, \mathrm{Se}^{\mathrm{II}}$, and $\mathrm{Se}^{\mathrm{III}}$ represents different sites of Se.

sole contributions only from strain effect. Hirshfeld charge analysis of the system before and after $\mathrm{Cu}$ substitution is presented in Table S5. It can clearly be seen that the sites having contributions from both ligand and strain effects have $\Delta G_{\mathrm{H}}$ close to 0 and hence show better activity.

In conclusion, we highlighted an in-depth understanding of the atomic strain engineering in the system through the introduction of a smaller atom with the assistance of both experimental and theoretical studies. Cu substitution in $\mathrm{Pd}_{17} \mathrm{Se}_{15}$ system imposes tensile stress to the system, which then enhances the activity of the system through modulation of the electronic structure. These nanoparticles are highly stable during 30000 cycles of accelerated degradation testing and have recorded TOF value of $126.3 \mathrm{~s}^{-1}$ at an overpotential of $200 \mathrm{mV}$. These studies can potentially impact designing many new catalysts for HER and/or other electrochemical studies by atomic strain engineering through appropriate chemical substitution. A detailed understanding of this compound will help in designing and redefining our concepts of strain engineering to enhance the activity of such catalysts.

\section{ASSOCIATED CONTENT}

\section{S Supporting Information}

The Supporting Information is available free of charge on the ACS Publications website at DOI: 10.1021/acsenergylett.8b01965.

Characterization, experimental details, XRD, EDAX, XPS, electrochemical performance results, additional experiment results, DFT calculations (PDF)

\section{AUTHOR INFORMATION}

\section{Corresponding Author}

*S. C. Peter. E-mail: sebastiancp@jncasr.ac.in.

ORCID $\odot$

Saurav Ch. Sarma: 0000-0002-6941-9702

Vidyanshu Mishra: 0000-0002-8660-2859

Sebastian C. Peter: 0000-0002-5211-446X

Notes

The authors declare no competing financial interest.

\section{ACKNOWLEDGMENTS}

Financial support from the Department of Science and Technology (DST) (Grant SB/FT/CS-07/2011), Sheikh Saqr Laboratory and Jawaharlal Nehru Centre for Advanced Scientific Research (JNCASR) is gratefully acknowledged. Parts of this research were also carried out at the light source PETRA III at DESY, a member of the Helmholtz Association (HGF) and we thank Dr. Wolfgang A. Caliebe for assistance in using PETRA III beamline P64 at DESY, Germany. We also thank DST for the financial assistance for the measurement at DESY. We also thank DST for the financial assistance for the measurement at DESY. We are grateful to Prof. C.N.R. Rao for his constant support and encouragement.

\section{REFERENCES}

(1) Bhowmik, T.; Kundu, M. K.; Barman, S. Palladium NanoparticleGraphitic Carbon Nitride Porous Synergistic Catalyst for Hydrogen Evolution/Oxidation Reactions over a Broad Range of $\mathrm{pH}$ and Correlation of Its Catalytic Activity with Measured Hydrogen Binding Energy. ACS Catal. 2016, 6 (3), 1929-1941.

(2) Chia, X.; Sutrisnoh, N. A. A.; Pumera, M. Tunable Pt $-\mathrm{MoS}_{\mathrm{x}}$ Hybrid Catalysts for Hydrogen Evolution. ACS Appl. Mater. Interfaces 2018, 10 (10), 8702-8711.

(3) Hammer, B.; Norskov, J. K. Electronic Factors Determining the Reactivity of Metal Surfaces. Surf. Sci. 1995, 343 (3), 211-220.

(4) Jia, Q. Y.; Caldwell, K.; Strickland, K.; Ziegelbauer, J. M.; Liu, Z. Y.; Yu, Z. Q.; Ramaker, D. E.; Mukerjee, S. Improved Oxygen Reduction Activity and Durability of Dealloyed $\mathrm{PtCo}_{\mathrm{x}}$ Catalysts for Proton Exchange Membrane Fuel Cells: Strain, Ligand, and Particle Size Effects. ACS Catal. 2015, 5 (1), 176-186.

(5) Liang, K.; Yan, Y.; Guo, L.; Marcus, K.; Li, Z.; Zhou, L.; Li, Y.; Ye, R.; Orlovskaya, N.; Sohn, Y.-H.; et al. Strained $\mathrm{W}\left(\mathrm{Se}_{\mathrm{x}} \mathrm{S}_{1-\mathrm{x}}\right)_{2}$ Nanoporous Films for Highly Efficient Hydrogen Evolution. ACS Energy Lett. 2017, 2 (6), 1315-1320.

(6) Hwang, D. Y.; Choi, K. H.; Park, J. E.; Suh, D. H. Highly Efficient Hydrogen Evolution Reaction by Strain and Phase Engineering in Composites of Pt and $\mathrm{MoS}_{2}$ Nano-scrolls. Phys. Chem. Chem. Phys. 2017, 19 (28), 18356-18365.

(7) Yan, K.; Maark, T. A.; Khorshidi, A.; Sethuraman, V. A.; Peterson, A. A.; Guduru, P. R. The Influence of Elastic Strain on Catalytic Activity in the Hydrogen Evolution Reaction. Angew. Chem., Int. Ed. 2016, 55 (21), 6175-6181.

(8) Sabatier, P. Hydrogénations et Deshydrogénations par. Catalyse. Ber. Dtsch. Chem. Ges. 1911, 44, 1984-2001.

(9) Yan, K.; Kim, S. K.; Khorshidi, A.; Guduru, P. R.; Peterson, A. A. High Elastic Strain Directly Tunes the Hydrogen Evolution Reaction on Tungsten Carbide. J. Phys. Chem. C 2017, 121 (11), 6177-6183.

(10) Han, Z.; Guohua, G.; Mingliang, D.; Jinhui, Z.; Kai, W.; Wenbo, W.; Xu, C.; Yong, L.; Piming, M.; Weifu, D.; et al. Atomic-Scale Core/ Shell Structure Engineering Induces Precise Tensile Strain to Boost Hydrogen Evolution Catalysis. Adv. Mater. 2018, 30 (26), 1707301.

(11) Liu, Z.; Qi, J.; Liu, M.; Zhang, S.; Fan, Q.; Liu, H.; Liu, K.; Zheng, H.; Yin, Y.; Gao, C. Aqueous Synthesis of Ultrathin Platinum/NonNoble Metal Alloy Nanowires for Enhanced Hydrogen Evolution Activity. Angew. Chem., Int. Ed. 2018, 57, 11678.

(12) Pu, Z.; Amiinu, I. S.; Kou, Z.; Li, W.; Mu, S. RuP 2 -Based Catalysts with Platinum-like Activity and Higher Durability for the Hydrogen Evolution Reaction at All pH Values. Angew. Chem., Int. Ed. 2017, 56 (38), 11559-11564.

(13) Huang, Z.-F.; Song, J.; Li, K.; Tahir, M.; Wang, Y.-T.; Pan, L.; Wang, L.; Zhang, X.; Zou, J.-J. Hollow Cobalt-Based Bimetallic Sulfide Polyhedra for Efficient All-pH-Value Electrochemical and Photocatalytic Hydrogen Evolution. J. Am. Chem. Soc. 2016, 138 (4), 13591365.

(14) Roger, I.; Moca, R.; Miras, H. N.; Crawford, K. G.; Moran, D. A. J.; Ganin, A. Y.; Symes, M. D. The Direct Hydrothermal Deposition of Cobalt-doped $\mathrm{MoS}_{2}$ onto Fluorine-doped $\mathrm{SnO}_{2}$ Substrates for Catalysis 
of the Electrochemical Hydrogen Evolution Reaction. J. Mater. Chem. A 2017, 5 (4), 1472-1480.

(15) Zhong, X.; Sun, Y.; Chen, X.; Zhuang, G.; Li, X.; Wang, J.-G. Mo Doping Induced More Active Sites in Urchin-Like $\mathrm{W}_{18} \mathrm{O}_{49}$ Nanostructure with Remarkably Enhanced Performance for Hydrogen Evolution Reaction. Adv. Funct. Mater. 2016, 26 (32), 5778-5786.

(16) Liu, B.; Zhao, Y.-F.; Peng, H.-Q.; Zhang, Z.-Y.; Sit, C.-K.; Yuen, M.-F.; Zhang, T.-R.; Lee, C.-S.; Zhang, W.-J. Nickel-Cobalt Diselenide 3D Mesoporous Nanosheet Networks Supported on Ni Foam: An AllpH Highly Efficient Integrated Electrocatalyst for Hydrogen Evolution. Adv. Mater. 2017, 29 (19), 1606521.

(17) Liu, W.; Hu, E. Y.; Jiang, H.; Xiang, Y. J.; Weng, Z.; Li, M.; Fan, Q.; Yu, X. Q.; Altman, E. I.; Wang, H. L. A Highly Active and Stable Hydrogen Evolution Catalyst Based on Pyrite-structured Cobalt Phosphosulfide. Nat. Commun. 2016, 7, 10771.

(18) Kibsgaard, J.; Jaramillo, T. F. Molybdenum Phosphosulfide: An Active, Acid-Stable, Earth-Abundant Catalyst for the Hydrogen Evolution Reaction. Angew. Chem., Int. Ed. 2014, 53 (52), 1443314437.

(19) Li, J.; Li, F.; Guo, S.-X.; Zhang, J.; Ma, J. PdCu@Pd Nanocube with Pt-like Activity for Hydrogen Evolution Reaction. ACS Appl. Mater. Interfaces 2017, 9 (9), 8151-8160.

(20) Xu, Y.; Yin, S.; Li, C.; Deng, K.; Xue, H.; Li, X.; Wang, H.; Wang, L. Low-Ruthenium-Content NiRu Nanoalloys Encapsulated in Nitrogen-Doped Carbon as Highly Efficient and pH-universal Electrocatalysts for the Hydrogen Evolution Reaction. J. Mater. Chem. A 2018, 6 (4), 1376-1381.

(21) Chen, P. Z.; Zhou, T. P.; Chen, M. L.; Tong, Y.; Zhang, N.; Peng, X.; Chu, W. S.; Wu, X. J.; Wu, C. Z.; Xie, Y. Enhanced Catalytic Activity in Nitrogen-Anion Modified Metallic Cobalt Disulfide Porous Nanowire Arrays for Hydrogen Evolution. ACS Catal. 2017, 7 (11), $7405-7411$.

(22) Youn, D. H.; Han, S.; Kim, J. Y.; Kim, J. Y.; Park, H.; Choi, S. H.; Lee, J. S. Highly Active and Stable Hydrogen Evolution Electrocatalysts Based on Molybdenum Compounds on Carbon Nanotube-Graphene Hybrid Support. ACS Nano 2014, 8 (5), 5164-5173.

(23) Gu, Y.; Chen, S.; Ren, J.; Jia, Y. A.; Chen, C.; Komarneni, S.; Yang, D.; Yao, X. Electronic Structure Tuning in $\mathrm{Ni}_{3} \mathrm{FeN} / \mathrm{r}-\mathrm{GO}$ Aerogel toward Bifunctional Electrocatalyst for Overall Water Splitting. ACS Nano 2018, 12 (1), 245-253.

(24) Chen, Y. C.; Lu, A. Y.; Lu, P.; Yang, X. L.; Jiang, C. M.; Mariano, M.; Kaehr, B.; Lin, O.; Taylor, A.; Sharp, I. D.; et al. Structurally Deformed $\mathrm{MoS}_{2}$ for Electrochemically Stable, Thermally Resistant, and Highly Efficient Hydrogen Evolution Reaction. Adv. Mater. 2017, 29 (44), 1703863.

(25) Feng, L.-L.; Yu, G.; Wu, Y.; Li, G.-D.; Li, H.; Sun, Y.; Asefa, T.; Chen, W.; Zou, X. High-Index Faceted $\mathrm{Ni}_{3} \mathrm{~S}_{2}$ Nanosheet Arrays as Highly Active and Ultrastable Electrocatalysts for Water Splitting. J. Am. Chem. Soc. 2015, 137 (44), 14023-14026.

(26) Demir, E.; Akbayrak, S.; Önal, A. M.; Özkar, S. NanoceriaSupported Ruthenium(0) Nanoparticles: Highly Active and Stable Catalysts for Hydrogen Evolution from Water. ACS Appl. Mater. Interfaces 2018, 10 (7), 6299-6308.

(27) Li, H.; Qian, X.; Xu, C.; Huang, S.; Zhu, C.; Jiang, X.; Shao, L.; Hou, L. Hierarchical Porous $\mathrm{Co}_{9} \mathrm{~S}_{8} /$ Nitrogen-Doped Carbon@ $@ \mathrm{MoS}_{2}$ Polyhedrons as $\mathrm{pH}$ Universal Electrocatalysts for Highly Efficient Hydrogen Evolution Reaction. ACS Appl. Mater. Interfaces 2017, 9 (34), 28394-28405.

(28) Zhang, J.; Liu, Y.; Sun, C.; Xi, P.; Peng, S.; Gao, D.; Xue, D. Accelerated Hydrogen Evolution Reaction in $\mathrm{CoS}_{2}$ by Transition-Metal Doping. ACS Energy Lett. 2018, 3, 779-786.

(29) Daniele, S.; Line, J.; Søren, S.; Kurt, S. Method for Determining Optimal Supercell Representation of Interfaces. J. Phys.: Condens. Matter 2017, 29 (18), 185901.

(30) Li, Y.; Wang, H.; Xie, L.; Liang, Y.; Hong, G.; Dai, H. $\mathrm{MoS}_{2}$ Nanoparticles Grown on Graphene: An Advanced Catalyst for the Hydrogen Evolution Reaction. J. Am. Chem. Soc. 2011, 133 (19), 7296-7299.
(31) Tran, T. D.; Nguyen, T. M. t.; Le, H. V.; Nguyen, D. N.; Truong, Q. D.; Tran, P. D. Gold nanoparticle as an Outstanding Catalyst for the Hydrogen Evolution Reaction. Chem. Commun. 2018, 54, 3363-3366.

(32) Ni, B.; He, P.; Liao, W.; Chen, S.; Gu, L.; Gong, Y.; Wang, K.; Zhuang, J.; Song, L.; Zhou, G.; et al. Surface Oxidation of AuNi Heterodimers to Achieve High Activities toward Hydrogen/Oxygen Evolution and Oxygen Reduction Reactions. Small 2018, 14, 1703749.

(33) Popczun, E. J.; McKone, J. R.; Read, C. G.; Biacchi, A. J.; Wiltrout, A. M.; Lewis, N. S.; Schaak, R. E. Nanostructured Nickel Phosphide as an Electrocatalyst for the Hydrogen Evolution Reaction. J. Am. Chem. Soc. 2013, 135 (25), 9267-9270.

(34) Bose, R.; Jothi, V. R.; Koh, B.; Jung, C.; Yi, S. C. Molybdenum Sulphoselenophosphide Spheroids as an Effective Catalyst for Hydrogen Evolution Reaction. Small 2018, 14 (8), 1703862.

(35) Wu, T.; Stone, M. L.; Shearer, M. J.; Stolt, M. J.; Guzei, I. A.; Hamers, R. J.; Lu, R. F.; Deng, K. M.; Jin, S.; Schmidt, J. R. Crystallographic Facet Dependence of the Hydrogen Evolution Reaction on CoPS: Theory and Experiments. ACS Catal. 2018, 8 (2), 1143-1152.

(36) Drouet, S.; Creus, J.; Colliere, V.; Amiens, C.; Garcia-Anton, J.; Sala, X.; Philippot, K. A Porous $\mathrm{Ru}$ nanomaterial as an Efficient Electrocatalyst for the Hydrogen Evolution Reaction Under Acidic and Neutral Conditions. Chem. Commun. 2017, 53 (85), 11713-11716.

(37) Yin, J.; Fan, Q.; Li, Y.; Cheng, F.; Zhou, P.; Xi, P.; Sun, S. Ni-C$\mathrm{N}$ Nanosheets as Catalyst for Hydrogen Evolution Reaction. J. Am. Chem. Soc. 2016, 138 (44), 14546-14549.

(38) Gomes, W. C. M.; Neto, A. d. O. W.; Pimentel, P. M.; Melo, D. M. d. A.; Silva, F. R. G. e. An In-situ X-ray Absorption Spectroscopy Study of Copper Nanoparticles in Microemulsion. Colloids Surf., A 2013, 426, 18-25.

(39) Lukowski, M. A.; Daniel, A. S.; Meng, F.; Forticaux, A.; Li, L. S.; Jin, S. Enhanced Hydrogen Evolution Catalysis from Chemically Exfoliated Metallic $\mathrm{MoS}_{2}$ Nanosheets. J. Am. Chem. Soc. 2013, 135 (28), 10274-10277.

(40) Kukunuri, S.; Austeria, P. M.; Sampath, S. Electrically Conducting Palladium Selenide $\left(\mathrm{Pd}_{4} \mathrm{Se}, \mathrm{Pd}_{17} \mathrm{Se}_{15}, \mathrm{Pd}_{7} \mathrm{Se}_{4}\right)$ Phases: Synthesis and Activity Towards Hydrogen Evolution Reaction. Chem. Commun. 2016, 52 (1), 206-209.

(41) Kitchin, J. R.; Nørskov, J. K.; Barteau, M. A.; Chen, J. G. Role of Strain and Ligand Effects in the Modification of the Electronic and Chemical Properties of Bimetallic Surfaces. Phys. Rev. Lett. 2004, 93 (15), 156801.

(42) Cho, J.; Lee, S.; Yoon, S. P.; Han, J.; Nam, S. W.; Lee, K.-Y.; Ham, $\mathrm{H}$. C. Role of Heteronuclear Interactions in Selective $\mathrm{H}_{2}$ Formation from $\mathrm{HCOOH}$ Decomposition on Bimetallic $\mathrm{Pd} / \mathrm{M}(\mathrm{M}=$ Late Transition FCC Metal) Catalysts. ACS Catal. 2017, 7 (4), 2553-2562. 